Atmos. Chem. Phys., 13, 10721-10732, 2013

www.atmos-chem-phys.net/13/10721/2013/

doi:10.5194/acp-13-10721-2013

(c) Author(s) 2013. CC Attribution 3.0 License.

\title{
Modeling the surface tension of complex, reactive organic-inorganic mixtures
}

\author{
A. N. Schwier ${ }^{1, *}$, G. A. Viglione ${ }^{1}$, Z. Li ${ }^{1,{ }^{* *}}$, and V. Faye McNeill ${ }^{1}$ \\ ${ }^{1}$ Department of Chemical Engineering, Columbia University, New York, NY 10027, USA \\ * now at: Laboratoire de Météorologie Physique CNRS, UMR6016, Observatoire de Physique du Globe de Clermont-Ferrand, \\ Université Blaise Pascal, France \\ ** now at: University of Florida, Department of Chemical Engineering, Florida, USA
}

Correspondence to: V. Faye McNeill (vfm2103@columbia.edu)

Received: 9 December 2012 - Published in Atmos. Chem. Phys. Discuss.: 8 January 2013

Revised: 16 September 2013 - Accepted: 2 October 2013 - Published: 5 November 2013

\begin{abstract}
Atmospheric aerosols can contain thousands of organic compounds which impact aerosol surface tension, affecting aerosol properties such as heterogeneous reactivity, ice nucleation, and cloud droplet formation. We present new experimental data for the surface tension of complex, reactive organic-inorganic aqueous mixtures mimicking tropospheric aerosols. Each solution contained 2-6 organic compounds, including methylglyoxal, glyoxal, formaldehyde, acetaldehyde, oxalic acid, succinic acid, leucine, alanine, glycine, and serine, with and without ammonium sulfate. We test two semi-empirical surface tension models and find that most reactive, complex, aqueous organic mixtures which do not contain salt are well described by a weighted SzyszkowskiLangmuir (S-L) model which was first presented by Henning et al. (2005). Two approaches for modeling the effects of salt were tested: (1) the Tuckermann approach (an extension of the Henning model with an additional explicit salt term), and (2) a new implicit method proposed here which employs experimental surface tension data obtained for each organic species in the presence of salt used with the Henning model. We recommend the use of method (2) for surface tension modeling of aerosol systems because the Henning model (using data obtained from organic-inorganic systems) and Tuckermann approach provide similar modeling results and goodness-of-fit $\left(\chi^{2}\right)$ values, yet the Henning model is a simpler and more physical approach to modeling the effects of salt, requiring less empirically determined parameters.
\end{abstract}

\section{Introduction}

Surface-active organics (surfactants) self-assemble at the gas-aqueous interface, where they may impact the heterogeneous reactivity and ice nucleating ability of aerosols (McNeill et al., 2013). Surfactants can impact the cloud nucleating ability of atmospheric aerosols by lowering the surface tension at the moment of activation, thus influencing the supersaturation required for cloud droplet activation as described by Köhler theory (Asa-Awuku et al., 2008; Facchini et al., 1999, 2000; Hitzenberger et al., 2002; Kiss et al., 2005; Novakov and Penner, 1993; Salma et al., 2006; Shulman et al., 1996). Up to thousands of surface-active compounds, many of which remain unspeciated, can be present in ambient aerosols, and the combined effect of these species on surface tension is highly dependent on aerosol composition (ionic content, $\mathrm{pH}$ ) and environmental conditions (temperature, relative humidity). Chemical reactions among aerosol components may also influence surface tension.

In order to improve our understanding of surfactant film formation in mixed organic-inorganic aerosols, it is desirable to model aerosol surface tension. In view of a bottomup approach to modeling surface tension in aerosols, laboratory studies have been performed on aqueous solutions containing single organic species, with and without inorganic electrolytes present (Aumann et al., 2010; Aumann and Tabazadeh, 2008; Cosman et al., 2008; Cosman and Bertram, 2008; Dash and Mohanty, 1997; Ekström et al., 2009; Hyvärinen et al., 2006; Knopf and Forrester, 2011; Nozière et al., 2010; Reid et al., 2011; Riipinen et al., 2007; 
Sareen et al., 2010; Schwier et al., 2012; Shapiro et al., 2009; Shulman et al., 1996; Tuckermann, 2007; Varga et al., 2007). Fewer studies have focused on specific atmospherically relevant complex mixtures of organics (Henning et al., 2005; Li et al., 2011; Schwier et al., 2010; Svenningsson et al., 2006; Topping et al., 2007; Tuckermann and Cammenga, 2004). The temperature-dependent relationship between organic carbon concentration and surface tension can be described by the semi-empirical Szyszkowski-Langmuir (S-L) equation (Langmuir, 1917),

$\sigma(T)=\sigma_{\mathrm{o}}(T)-a T \ln (1+b C)$,

where $\sigma_{\mathrm{o}}$ is the surface tension of the solution in the absence of organics, $T$ is temperature $(\mathrm{K}), C$ is the molality of the organic (mol carbon $\left(\mathrm{kg} \mathrm{H}_{2} \mathrm{O}\right)^{-1}$ ), and $a$ and $b$ are fit parameters corresponding to the organic. This equation has been used successfully to model surface tension depression in aqueous solutions by both isolated organics and complex mixtures (Facchini et al., 1999; Li et al., 2011; Schwier et al., 2010, 2012; Tuckermann, 2007). In different studies, Henning et al. (2005) and Tuckermann and Cammenga (2004) used modified S-L equations to describe nonreactive organic systems, assuming linearly additive contributions of each organic species to the total surface tension depression. Henning et al. (2005) was accurately able to model the experimental results of binary mixtures of adipic and succinic acid in $2 \% \mathrm{NaCl}$ solutions (by mass), whereas Tuckermann and Cammenga (2004) described complex mixtures of up to six organic components (humic acid, pinonic acid, azelaic acid, levoglucosan, 3-hydroxybenzoic acid, 3hydroxybutanoic acid) well.

Other surface tension models capable of describing multicomponent systems (multiple organics and electrolytes) have been developed based on thermodynamic principles and experimental data. Binary and higher-order inorganic systems (with some addition of organic acids) have been described by using thermodynamic analysis (Hu and Lee, 2004; Li et al., 1999; $\mathrm{Li}$ and $\mathrm{Lu}, 2001$ ). Complex organic systems have also been described by thermodynamic analysis, requiring, for example, surface tension or adsorption isotherm data, molar surface area and surface pressure of the surfactants and solvent (Fainerman et al., 2002; Fainerman and Miller, 2001); however, many thermodynamic properties of the organics relevant for atmospheric aerosols are unknown. Topping et al. (2007) studied binary and higher-order systems of organics (levoglucosan, succinic acid, fulvic acid, pinonic acid, oxalic acid) in salt solutions $\left(\left(\mathrm{NH}_{4}\right)_{2} \mathrm{SO}_{4}, \mathrm{NaCl}, \mathrm{NH}_{4} \mathrm{NO}_{3}\right)$ and compared experimental results with those of different modeling techniques, including those of $\mathrm{Li}$ and $\mathrm{Lu}$ (2001), Suarez et al. (1989), and Tamura et al. (1955). They found that aqueous solutions of isolated and mixed organics were described well by the model of $\mathrm{Li}$ and $\mathrm{Lu}$ (2001) or modified versions thereof, but that the models did not perform as well after inorganics were introduced. Booth et al. (2009) followed a similar procedure as Topping et al. (2007) and modeled $\mathrm{C}_{2}-$ $\mathrm{C}_{6}$ straight-chain dicarboxylic acids with $\left(\mathrm{NH}_{4}\right)_{2} \mathrm{SO}_{4}, \mathrm{NaCl}$, $\mathrm{Na}_{2} \mathrm{SO}_{4}$, or $\mathrm{NH}_{4} \mathrm{NO}_{3}$ using three different thermodynamic models. They found that no model accurately described the experimental systems, although the methodology of $\mathrm{Li}$ and Lu (2001) performed the best, and they recommended including surface-bulk partitioning and "salting-out" of the organic material to improve the agreement between model and experiment.

While much progress has been made on modeling nonreactive systems, aqueous aerosols and cloud droplets provide an environment for chemical reactions between watersoluble organics. This has recently been identified as an important source of secondary organic aerosol (SOA) material (Ervens and Volkamer, 2010; Li et al., 2011; Nopmongcol et al., 2007; Sareen et al., 2010; Schwier et al., 2010; Shapiro et al., 2009; Tan et al., 2010). Carbonyl-containing species, such as glyoxal, methylglyoxal, and acetaldehyde, have been shown to react with one another in aqueous solution (Li et al., 2011; Sareen et al., 2010; Shapiro et al., 2009) as well as with amino acids. Recently, Wang et al. (2010) proposed the Mannich reaction pathway to explain the presence of high molecular weight nitrogen-containing organic salts in collected urban Shanghai aerosol. Nozière and Córdova (2008) studied different amino acids and acetaldehyde at acidic conditions and determined that cross-reaction products were formed either by the Mannich reaction pathway or through aldol condensation. De Haan and coworkers investigated SOA formation of glyoxal and methylglyoxal with amino acids and amine functional groups and detected the presence of high molecular weight oligomers and nitrogencontaining compounds (De Haan et al., 2009a, b, 2010).

Few studies have attempted to model the surface tension behavior of complex systems where many of the species can interact and undergo aqueous-phase reactions to form different compounds (Li et al., 2011; Schwier et al., 2010); unsurprisingly, this task has proven challenging. The surface tension depression of an aqueous mixture containing methylglyoxal and glyoxal, which undergo similar aqueous-phase chemistry, was successfully modeled using a sum of the individual organic contributions to surface tension, even though cross-reactions were found to be responsible for a large portion of the organic mass present (Schwier et al., 2010). Based on the structure of the oligomers formed in this system (e.g., Sareen et al., 2010; Schwier et al., 2010) it seems reasonable that in a population of oligomers formed by methylglyoxal and glyoxal self- and cross-reactions, the surface tension depression is roughly proportional to the hydrophobic surface area, which is contributed solely by the methylglyoxal free methyl groups.

However, the surface tension depression of tertiary reactive organic systems (acetaldehyde, formaldehyde, and methylglyoxal) was consistently under-predicted by the additive Henning model (Li et al., 2011). The presence of inorganic components in these systems also brings in additional 
Table 1. Experimental mixtures studied in this work. All concentrations are given in molarity (M). The symbol "v" indicates that the concentration of the organic was variable throughout the experiment. In Mixtures \#14-16, the total organic concentration was either 0.5 or $0.05 \mathrm{M}$; in Mixture \#17, the total organic concentration ranged from 0 to $1 \mathrm{M}$. The $k$ parameter was calculated using Eq. (6), as described in Sect. 3.5. See text for more details.

\begin{tabular}{|c|c|c|c|c|c|c|c|c|c|c|c|c|}
\hline Mixture & $\left(\mathrm{NH}_{4}\right)_{2} \mathrm{SO}_{4}$ & Acetaldehyde & Formaldehyde & Glyoxal & Methylglyoxal & Alanine & Glycine & Serine & Leucine & Oxalic Acid & Succinic Acid & $k$ \\
\hline$\# 1$ & 3.1 & 0.05 & & & & $\leq 0.02$ & & & & & & $-0.06 \pm 0.03$ \\
\hline \#3 & 3.1 & 0.05 & & & & & $\leq 0.02$ & & & & & $0.08 \pm 0.05$ \\
\hline \#4 & 0 & 0.05 & & & & & $\leq 0.02$ & & & & & - \\
\hline \#6 & 0 & 0.05 & & & & & & $\leq 0.02$ & & & & - \\
\hline \#7 & 3.1 & 0.05 & & & & & & & $\leq 0.02$ & & & $-0.15 \pm 0.04$ \\
\hline \#8 & 0 & 0.05 & & & & & & & $\leq 0.02$ & & & - \\
\hline \#9 & 3.1 & & & 0.05 & & & $\leq 0.02$ & & & & & $0.06 \pm 0.02$ \\
\hline$\# 12$ & 3.1 & & & 0.05 & & & & $\leq 0.02$ & & & & $0.07 \pm 0.02$ \\
\hline$\# 13$ & 3.1 & & & & 0.05 & & & $\leq 0.02$ & & & & $-1.64 \pm 0.13$ \\
\hline \multirow[t]{2}{*}{$\# 14$} & 3.1 & $\mathrm{v}$ & & & $\mathrm{v}$ & & & & & & & $-1.45 \pm 0.11(0.05 \mathrm{M})$ \\
\hline & 3.1 & & & & & & & & & & & $\begin{array}{l}-1.42 \pm 0.05(0.5 \mathrm{M}) \\
-1.79 \pm 0.04\end{array}$ \\
\hline \multirow[t]{2}{*}{$\# 16$} & 3.1 & $\mathrm{v}$ & $\mathrm{v}$ & & $\mathrm{v}$ & & & & & & & $-1.56 \pm 0.12(1: 1)$ \\
\hline & & & & & & & & & & & & $-1.90 \pm 0.12(1: 3)$ \\
\hline \#17 & 3.1 & $\mathrm{v}$ & $\mathrm{v}$ & $\mathrm{v}$ & $\mathrm{v}$ & & & & & $\mathrm{v}$ & $\mathrm{v}$ & $-0.40 \pm 0.03$ \\
\hline
\end{tabular}

uncertainties since the inorganic species may participate in the aqueous chemistry (Nozière et al., 2009, 2010; Nozière and Córdova, 2008; Sareen et al., 2010; Schwier et al., 2010), in addition to nonreactive salt-organic interactions (such as salting-out) which may influence surface tension ( $\mathrm{Li}$ et al., 1998; Matijevic and Pethica, 1958; Setschenow, 1889). Currently, few datasets exist with surface tension information for organics in near-saturated salt solutions, typical of atmospheric aerosols (Li et al., 2011; Schwier et al., 2010, 2012), so the effect of salts is still not well parameterized for use in models of aerosol surface tension.

Here, we present experimental measurements of surface tension in complex, reactive, aqueous organic-inorganic systems (2-6 organic compounds). We use this dataset to test semi-empirical approaches for modeling the surface tension of mixed organic-inorganic aqueous solutions and provide recommendations for modeling surface tension depression in aerosol systems.

\section{Experimental methods}

\subsection{Solution preparation}

Aqueous solutions were prepared and tested at $24 \mathrm{~h}$ after mixing for all systems analyzed (in order to allow the reactive system to equilibrate). The following organics were used in different combinations and concentrations to model complex surface tension effects: methylglyoxal (40 wt $\%$ aqueous stock solution, Aldrich), glyoxal (40 wt $\%$ aqueous stock solution, Alfa Aesar), formaldehyde ( $37 \mathrm{wt} \%$ aqueous stock solution, Sigma Aldrich), acetaldehyde (99.5\%, Sigma Aldrich), oxalic acid (dihydrate, Fisher Scientific), succinic acid (99\%, Acros Organics), DL-leucine (Sigma Aldrich), DL-alanine (99\%, Acros Organics), glycine (Fischer Scien- tific), and L-serine (Sigma Aldrich). The amino acids were chosen for this study due to their known presence in atmospheric aerosols and ice nucleation activity (Szyrmer and Zawadzki, 1997; Zhang and Anastasio, 2003) as well as their surfactant character (i.e., hydrophobicity from the $-\mathrm{R}$ side group). The different mixtures studied in this work are shown in Table 1. Most solutions were tested at atmospherically relevant concentrations and beyond ( $\leq 1 \mathrm{M}$ total organic) in order to elucidate the behavior of the mixture as a function of organic concentration; however, Zhang and Anastasio (2003) was used as a basis for atmospherically relevant amino acid in-particle concentrations. The concentration range was also limited by amino acid solubility. For the ternary mixtures, we used available data from Li et al. (2011).

Solutions were made in Millipore water alone or with ammonium sulfate at near-saturated concentrations $(3.1 \mathrm{M}$ $\left.\left(\mathrm{NH}_{4}\right)_{2} \mathrm{SO}_{4}\right)$ in order to mimic the composition of aqueous aerosols (Tang et al., 1997; Tang and Munkelwitz, 1994). The natural $\mathrm{pH}$ of solutions containing $\left(\mathrm{NH}_{4}\right)_{2} \mathrm{SO}_{4}$ varied from 2.7 to 5.9 ; in $\mathrm{H}_{2} \mathrm{O}$, the $\mathrm{pH}$ was slightly higher, typically between 4.3 and 5.7 (though it reached $\mathrm{pH} 8$ for some mixtures). Mixtures using methylglyoxal and glyoxal were slightly acidic due to the presence of trace impurities of pyruvic acid and glyoxylic acid from the $40 \mathrm{wt} \%$ stock solutions, respectively. All of the reaction mixtures fell within the bounds of atmospherically relevant $\mathrm{pH}$ for tropospheric aerosols ( pH 0-8) (Keene et al., 2004; Zhang et al., 2007). The solutions were stored in $100 \mathrm{~mL}$ Pyrex volumetric flasks at ambient temperature, without further protection from ambient light. The complex mixture involving 6 organics was studied at different total organic concentrations, but always with the same fixed relative ratios of the organics to one another, based on ambient field measurements: ambient inparticle concentrations of methylglyoxal, glyoxal, oxalic and 
Table 2. Ambient in-particle concentrations used to calculate the complex organic mixture ratios.

\begin{tabular}{lll}
\hline Species & $\begin{array}{l}\text { Ambient in-particle } \\
\text { concentration }\left(\mathrm{ng} \mathrm{m}^{-3}\right)\end{array}$ & Reference \\
\hline Acetaldehyde & 406 & Grosjean (1982) \\
Formaldehyde & 264 & \\
Glyoxal & 16.4 & Kawamura and Yasui (2005) \\
Methylglyoxal & 21.4 & \\
Oxalic acid & 233 & \\
Succinic acid & 53.9 & \\
\hline
\end{tabular}

succinic acids were taken from Kawamura and Yasui (2005), and acetaldehyde and formaldehyde in-particle concentrations were used from Grosjean (1982); all concentrations $\left(\mathrm{ng} \mathrm{m}^{-3}\right)$ are shown in Table 2. These concentrations were used to determine the in-particle mass wt $\%$ of each component. Assuming a specified total organic concentration (i.e., $1 \mathrm{M})$ and an average molecular weight of all the organic species, the relative mass amount (or volume amount) of each species was calculated based on the mass wt $\%$.

\subsection{Surface tension measurements}

Our approach for surface tension measurements has previously been described (Shapiro et al., 2009). Briefly, droplets of the bulk solutions formed at the tip of a $100 \mu \mathrm{L}$ syringe, where they equilibrated over timescales of 2-5 minutes at room temperature (approximately $25 \pm 1^{\circ} \mathrm{C}$ ). Image capture software was used to take an image of the droplet before it detached and fell from the syringe following the methodology of Anastasiadis et al. (1987). An edge detection software program was then used to analyze the droplet in MATLAB 7.0 (The MathWorks, Inc.) following Canny (1986). Surface tension was determined by Adamson and Gast (1997):

$\sigma=\frac{\Delta \rho g d_{\mathrm{e}}^{2}}{H}$,

where $\sigma$ is the surface tension, $\Delta \rho$ is the difference in the density between the surrounding gas medium (air) and the droplet, $g$ is the acceleration due to gravity, $d_{\mathrm{e}}$ is the equatorial diameter of the droplet and $H$ is the shape factor calculated following Juza (1997). An average of 5-8 drops was used to calculate the surface tension. The density of each solution was determined in triplicate using an analytical balance (Denver Instruments).

\subsection{Surface tension modeling}

Henning et al. (2005) modified the S-L equation to describe surface tension depression in complex nonreactive systems. The model accounts for a linear combination of the hypothetical total surface tension depression if each species accounted for all the organic material in the system, weighted by the fractional contribution of that species to total carbon content:
$\sigma(T)=\sigma_{\mathrm{o}}(T)-\sum_{i} \psi_{i} a_{i} T \ln \left(1+b_{i} C\right)$,

where $\psi_{i}$ is the carbon content of the $i$ th organic within the complex mixture $\left(\psi_{i}=C_{i} C^{-1}\right)$, and $a_{i}$ and $b_{i}$ are the fit parameters of the $i$ th organic.

We proposed previously (Schwier et al., 2010) to model surface tension depression in reactive inorganic-organic systems as a direct linear combination of the contribution of each organic species to the surface tension based on its concentration:

$\sigma(T)=\sigma_{\mathrm{o}}(T)-\sum_{i} a_{i} T \ln \left(1+b_{i} C_{i}\right)$.

This model was found to describe surface tension depression in mixed aqueous ammonium sulfate/glyoxal/methylglyoxal solutions well (Schwier et al., 2010). Since it does not take into account competition between organic species at the gas-aqueous interface, its application is limited to relatively low total surfactant concentrations.

The S-L equation has been used to describe aqueous organic solutions and organics in dilute salt solutions (Facchini et al., 1999; Henning et al., 2005; Tuckermann and Cammenga, 2004), although most aerosols are saturated with respect to the inorganic (Tang et al., 1997; Tang and Munkelwitz, 1994). Tuckermann (2007) extended the S-L equation to model the effects of electrolytes on the surface tension of mixed organic-inorganic solutions, with a separate term to account for salt-organic interactions as follows:

$\sigma(T)=\sigma_{H_{2} O}(T)+\left(\frac{\Delta \sigma}{\Delta c_{\text {salt }}}\right) c_{\text {salt }}$
$-a T \ln (1+b C)+k c_{\text {salt }} \ln (1+b C)$,

where $c_{\text {salt }}$ is the inorganic concentration, $\frac{\Delta \sigma}{\Delta c_{\text {salt }}}$ is the change in surface tension due to the inorganic species, and $k$ is a fit parameter. They found that $k$ behaved as a function of $C$, and that at small $C$ concentrations $\left(C \leq 0.01 \mathrm{~g} \mathrm{~L}^{-1}\right) k$ was positive, while at larger $C$ concentrations $k$ became negative and most likely converged. They stated that the term describing salt-organic interactions would need to be further specified from future studies. We have taken two approaches toward 
accounting for the effects of electrolytes in this study. In the first approach, we modified Eq. (5) as follows to describe complex systems with multiple organics:

$$
\begin{aligned}
& \sigma(T)=\sigma_{H_{2} O}(T)+\left(\frac{\Delta \sigma}{\Delta c_{\text {salt }}}\right) c_{\text {salt }} \\
& -\sum_{i} \psi_{i} a_{i} T \ln \left(1+b_{i} C\right)+k c_{\text {salt }} \sum_{i} \psi_{i} \ln \left(1+b_{i} C\right) .
\end{aligned}
$$

In the second approach, which we introduce for the first time here, we determined the fit parameters ( $a$ and $b$ ) from experimental measurements of surface tension depression by the individual organics in $3.1 \mathrm{M}\left(\mathrm{NH}_{4}\right)_{2} \mathrm{SO}_{4}$ solutions, and used these parameters in Eqs. (3) or (4) without any additional parameters.

In the following sections, for aqueous solutions of organics with no salt present, we present experimental data and semi-empirical model results using the fit parameters of the organics in water in Eqs. (3) and (4), represented as "Henning" or "Schwier2010", respectively $\left(\sigma_{\mathrm{o}}=72.5\right)$. For aqueous mixtures containing organics and $3.1 \mathrm{M}\left(\mathrm{NH}_{4}\right)_{2} \mathrm{SO}_{4}$, we present experimental data and complex semi-empirical modeled results using (1) the fit parameters of the organics in water ("W"), and (2) the fit parameters of the organics in $3.1 \mathrm{M}$ $\left(\mathrm{NH}_{4}\right)_{2} \mathrm{SO}_{4}$ ("S"), in Eqs. (3) and (4), represented as Henning or Schwier2010, respectively. In both semi-empirical models, for both fit parameters ( $\mathrm{W}$ and $\mathrm{S}$ ), we use $\sigma_{\mathrm{o}}=78.5$, the surface tension of $3.1 \mathrm{M}\left(\mathrm{NH}_{4}\right)_{2} \mathrm{SO}_{4}$, taken from Washburn (2003). Water fit parameters have been shown previously to describe organic mixtures in low concentrations of salt (Henning et al., 2005); this approach carries with it the implicit assumption that the addition of salt does not enhance the surface tension depression behavior of the organic in $\mathrm{H}_{2} \mathrm{O}$, via salting-out or any organic-inorganic reactions that may be occurring. Water fit parameters have been determined experimentally for multiple organics (Gaman, 2004; Svenningsson et al., 2006). Few experimental datasets exist for organics in high ionic concentration solutions, yet it has been shown that surface tension depression can deviate significantly in the presence of inorganic species. Some of the fit parameters have been previously published from this group (Li et al., 2011; Sareen et al., 2010); a list of all fit parameters in $\mathrm{H}_{2} \mathrm{O}$ and $\left(\mathrm{NH}_{4}\right)_{2} \mathrm{SO}_{4}$ used in this study can be found in the Supplement. Semi-empirical model results were determined by using a nonlinear least squares fit method, weighted by the standard deviation of the experimental surface tension data.

Using IGOR Pro, we determined the carbonconcentration-dependent $95 \%$ confidence intervals, $\Delta_{i}^{C I}(C)$, accounting for the correlation between the fit parameters, $a$ and $b$, for our isolated organic species $i$ in both aqueous and ionic solutions (for nonlinear equations, IGOR uses the linear term of a Taylor expansion). Due to the nonlinearity of the S-L equation, a Bayesian inference approach should be used for the most rigorous confidence interval treatment of correlated variables (we refer the reader to Blau et

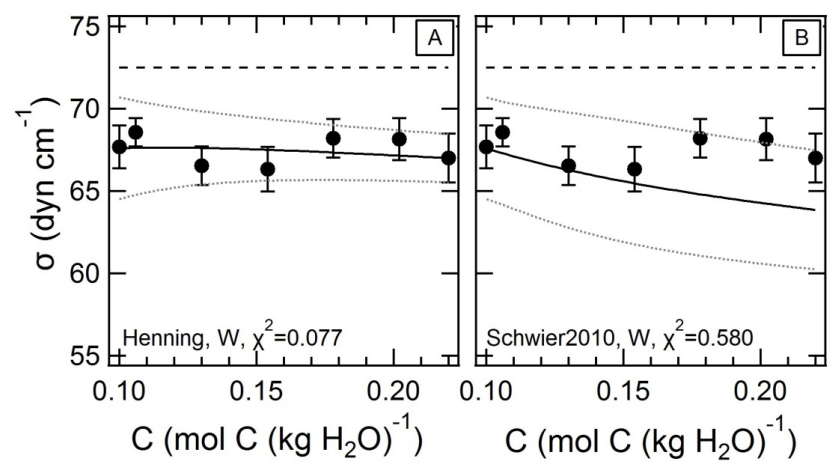

Fig. 1. 0.05 $\mathrm{M}$ acetaldehyde and varying amounts of leucine in Millipore $\mathrm{H}_{2} \mathrm{O}$. (A) and (B) are the Henning semi-empirical model (Eq. 3) and the Schwier2010 semi-empirical model (Eq. 4) with water fit parameters (W), respectively. In all figures, the black dots represent the experimental data, the black line is the semi-empirical model result, and the gray lines show the $95 \%$ confidence interval of the model result.

al. (2008) for such a treatment). The confidence intervals of the complex mixtures were then found by propagating the confidence regions from the isolated species based on either the Henning model or the Schwier2010 model (see the Supplement for more details).

\section{Results}

The following sections compare the ability of the different modeling methods characterized in Sect. 2.3 to describe each experimental dataset. Figures 1 and $\mathrm{S} 1-\mathrm{S} 3$, organics in aqueous solutions, have 2 plots: (a) and (b) are the Henning semiempirical model (Eq. 3) and the Schwier2010 semi-empirical model (Eq. 4) with water fit parameters (W), respectively. Figures 2-7 and S4-S12, organics in ionic solutions, have 4 plots: (a) and (c) are the Henning semi-empirical model and Schwier2010 semi-empirical model with $\left(\mathrm{NH}_{4}\right)_{2} \mathrm{SO}_{4}$ fit parameters (S), respectively; (b) and (d) are the same with water fit parameters (W), respectively. In all figures, the black dots represent the experimental data, the black solid line is the semi-empirical model result, and the gray dotted lines show the $95 \%$ confidence interval of the semi-empirical model result. For some complex mixtures, the confidence interval is truncated in one or more of the subplots; this is because experimental data to determine confidence intervals were not available for one or all of the organic species at high enough concentrations. Additionally, for some modeling methods, the confidence interval data were not available at all for some species at higher organic concentrations. For these instances, the confidence intervals used were constant values calculated as the average confidence interval over a range of lower concentrations where data were available for the necessary organic species. The relevant figures have this information listed in the captions. The black dashed line is the reference 


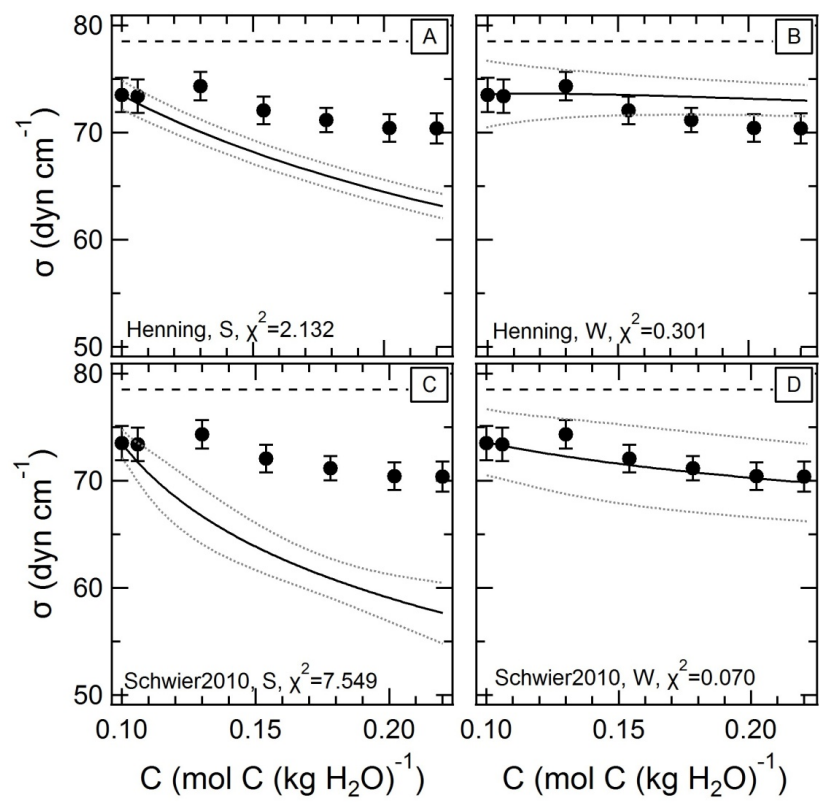

Fig. 2. $0.05 \mathrm{M}$ acetaldehyde and varying amounts of leucine in $3.1 \mathrm{M}\left(\mathrm{NH}_{4}\right)_{2} \mathrm{SO}_{4}$. (A) and (C) are the Henning semi-empirical model and Schwier2010 semi-empirical model with $\left(\mathrm{NH}_{4}\right)_{2} \mathrm{SO}_{4}$ fit parameters (S), respectively; (B) and (D) are the same with water fit parameters $(\mathrm{W})$, respectively. The average confidence interval value of leucine at lower concentrations $(0-0.12 \mathrm{~m})$ was used for the confidence interval contribution from leucine in (A) due to a lack of experimental data at high serine concentrations $(>0.12 \mathrm{~m})$.

surface tension of each solution in the absence of all organics $\left(72.5 \mathrm{dyn} \mathrm{cm}^{-1}\right.$ for aqueous solutions, $78.5 \mathrm{dyn} \mathrm{cm}^{-1}$ for ionic solutions). The $x$ axis is always given in terms of total organic carbon concentration ( $\mathrm{mol}$ carbon $\left(\mathrm{kg} \mathrm{H}_{2} \mathrm{O}\right)^{-1}$ ), so when applicable the first point of each figure is that of the constant concentration organic (Figs. 1-4, S1-9).

The "goodness of fit" $\left(\chi^{2}\right)$ of the semi-empirical model fit is also shown in each plot, calculated by

$\chi^{2}=\sum_{n=1}^{N} \frac{\left(\sigma_{\text {model }, n}-\sigma_{\text {exp }, n}\right)^{2}}{\sigma_{\exp , n}}$,

where $N$ is the number of observations in a given dataset, $\sigma_{\text {model }, n}$ is the semi-empirical model surface tension prediction, and $\sigma_{\exp , n}$ is the experimental surface tension value.

\subsection{Acetaldehyde + amino acids}

Solutions of $0.05 \mathrm{M}$ acetaldehyde and varying concentrations of alanine, glycine, leucine or serine $(0-0.02 \mathrm{M})$ were tested in both water and $3.1 \mathrm{M}\left(\mathrm{NH}_{4}\right)_{2} \mathrm{SO}_{4}$. Acetaldehyde has previously been shown to depress surface tension in aqueous and ionic solutions ( $\mathrm{Li}$ et al., 2011). Figures 1 and 2 show acetaldehyde-leucine mixtures in $\mathrm{H}_{2} \mathrm{O}$ and in $3.1 \mathrm{M}$ $\left(\mathrm{NH}_{4}\right)_{2} \mathrm{SO}_{4}$, respectively. The Henning approach describes the experimental data in water best (Fig. $1 \mathrm{a}, \chi^{2}=0.077$ ), but
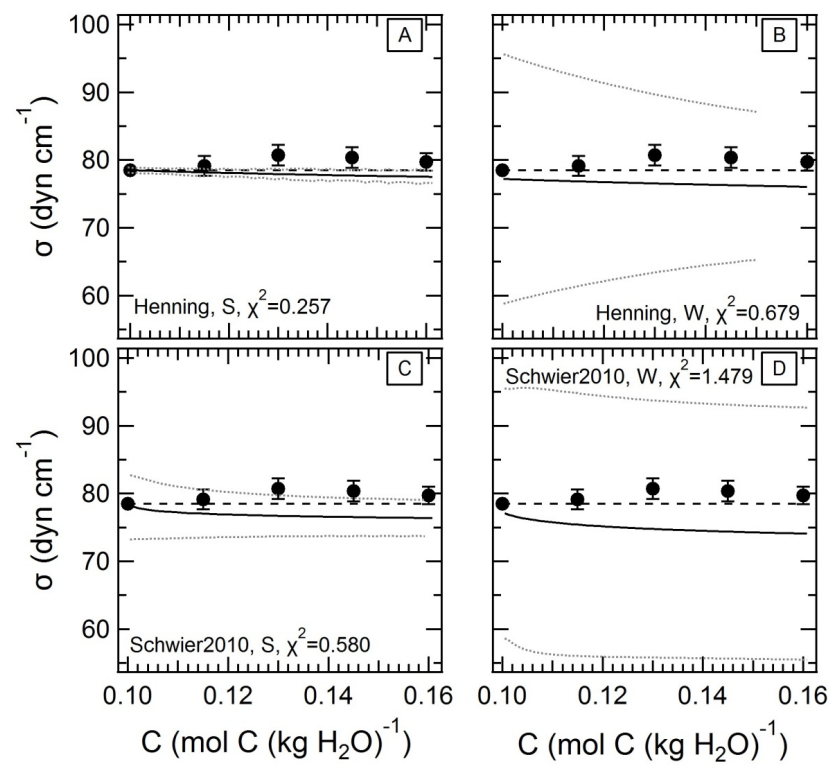

Fig. 3. $0.05 \mathrm{M}$ glyoxal with varying amounts of serine in $3.1 \mathrm{M}$ $\left(\mathrm{NH}_{4}\right)_{2} \mathrm{SO}_{4}$. (A) and (C) are the Henning semi-empirical model and Schwier2010 semi-empirical model with $\left(\mathrm{NH}_{4}\right)_{2} \mathrm{SO}_{4}$ fit parameters (S), respectively; (B) and (D) are the same with water fit parameters $(\mathrm{W})$, respectively. The abbreviated confidence interval in $(\mathbf{B})$ is due to the lack of serine surface tension data at high enough organic concentrations $(>0.15 \mathrm{~m})$.

in salt solutions the Schwier2010 semi-empirical model using water fit parameters best describes the system (Fig. 2d, $\left.\chi^{2}=0.070\right)$. The overestimation using salt parameters by both models indicates that any reaction products forming between acetaldehyde and leucine must be less surface active than the contributions of the individual organics. The Schwier2010 model using either water or salt fit parameters has a slightly larger confidence interval than the Henning model; this is due to the lack of a weighted term, $\psi_{i}$, which acts to narrow the deviation spread (Figs. 1b, 2c, d). In Fig. 2, the salt fit parameters over-predict the surface tension depression of the experimental data. The Henning model (Eq. 3) describes the acetaldehyde-serine experimental data in both $\mathrm{H}_{2} \mathrm{O}$ and $\left(\mathrm{NH}_{4}\right)_{2} \mathrm{SO}_{4}$ well (Fig. S3a $\left(\chi^{2}=0.097\right)$ and S6 $\left(\chi_{\text {avg }}^{2} \sim 0.201\right)$ ), while the Schwier2010 model slightly overestimates surface tension depression. In control experiments, no surface tension depression was observed in solutions of glycine or alanine in $3.1 \mathrm{M}\left(\mathrm{NH}_{4}\right)_{2} \mathrm{SO}_{4}$. The acetaldehyde-glycine and acetaldehyde-alanine mixtures in $\mathrm{H}_{2} \mathrm{O}$ and $\left(\mathrm{NH}_{4}\right)_{2} \mathrm{SO}_{4}$ are described by both semi-empirical models well, but in the presence of $\left(\mathrm{NH}_{4}\right)_{2} \mathrm{SO}_{4}$ the salt parameters describe the experimental data better (Figs. S1, S2, S4, and S5). 


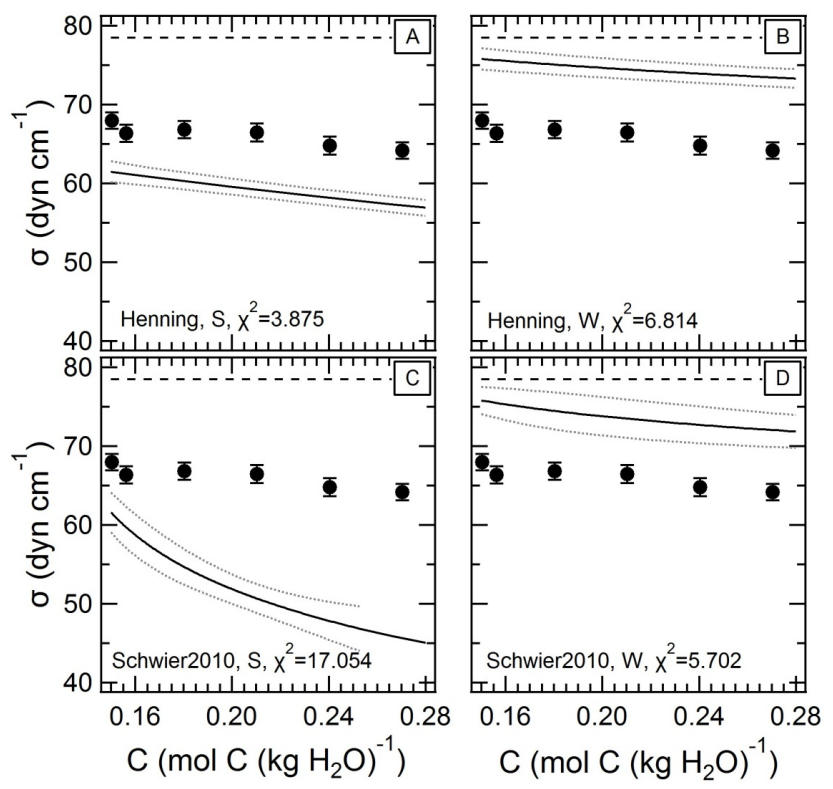

Fig. 4. $0.05 \mathrm{M}$ methylglyoxal with varying amounts of leucine in $3.1 \mathrm{M}\left(\mathrm{NH}_{4}\right)_{2} \mathrm{SO}_{4}$. (A) and (C) are the Henning semi-empirical model and Schwier2010 semi-empirical model with $\left(\mathrm{NH}_{4}\right)_{2} \mathrm{SO}_{4}$ fit parameters (S), respectively; (B) and (D) are the same with water fit parameters $(\mathrm{W})$, respectively. The average confidence interval value of leucine at lower concentrations $(0-0.12 \mathrm{~m})$ was used for the confidence interval contribution from leucine in (A) due to a lack of experimental data at high leucine concentrations $(>0.12 \mathrm{~m})$. The abbreviated confidence interval in $(\mathbf{C})$ is due to the same reason.

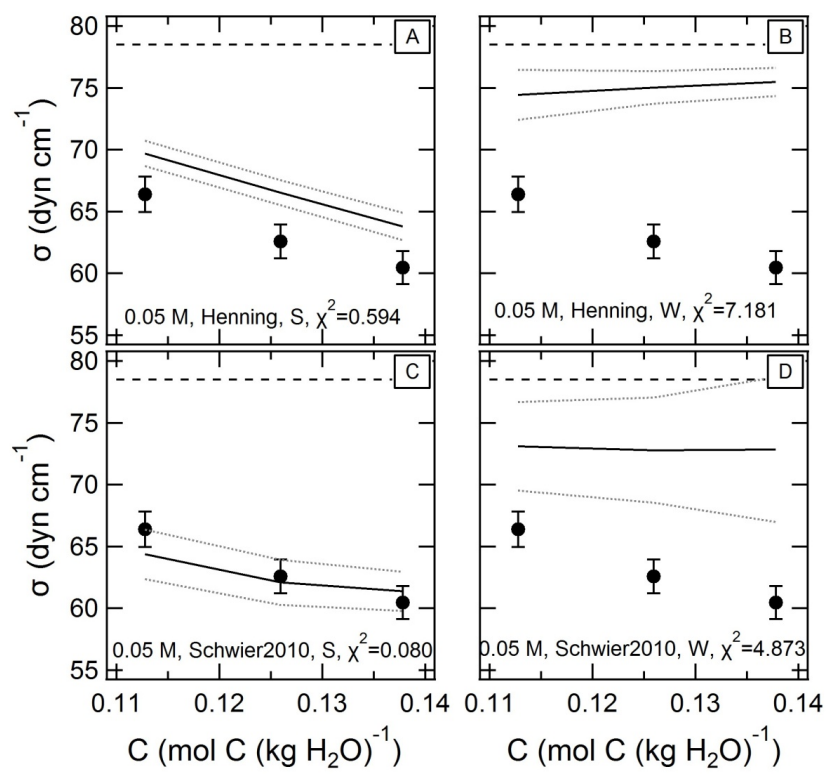

Fig. 5. $0.05 \mathrm{M}$ total organic with varying amounts of acetaldehyde and methylglyoxal in $3.1 \mathrm{M}\left(\mathrm{NH}_{4}\right)_{2} \mathrm{SO}_{4}$. (A) and (C) are the Henning semi-empirical model and Schwier2010 semi-empirical model with $\left(\mathrm{NH}_{4}\right)_{2} \mathrm{SO}_{4}$ fit parameters (S), respectively; (B) and (D) are the same with water fit parameters $(\mathrm{W})$, respectively.

\subsection{Glyoxal/methylglyoxal + amino acids}

Experimental data of $0.05 \mathrm{M}$ glyoxal with varying concentrations of serine $(0-0.02 \mathrm{M})$ is similarly represented by both semi-empirical models (Fig. 3, $\left(\chi_{\text {avg }}^{2}=0.749\right)$ ). Glyoxal is not surface active in water or salt solutions (Shapiro et al., 2009), yet serine is. It is possible that glyoxal is affecting the ability of serine to depress surface tension by occupying available surface sites at the interface; reaction products between glyoxal and serine that are less surface active than serine itself could also be forming. This could explain why the semi-empirical models slightly overestimate the surface tension of the experimental data. Mixtures of $0.05 \mathrm{M}$ glyoxal and varying amounts of glycine $(0-0.02 \mathrm{M})$ in $\left(\mathrm{NH}_{4}\right)_{2} \mathrm{SO}_{4}$ have no visible surface tension depression (Fig. S7), because neither isolated organic was found to be surface active in $\left(\mathrm{NH}_{4}\right)_{2} \mathrm{SO}_{4}$. Models using salt fit parameters give a nearly straight line $\sigma \sim 78.5$ (Fig. S7a, c, $\chi^{2}=0.033$ ). Glycine is surface active in $\mathrm{H}_{2} \mathrm{O}$ though, so water fit parameters overestimate the surface tension depression of these organics in $\left(\mathrm{NH}_{4}\right)_{2} \mathrm{SO}_{4}$ solutions (Fig. S7b, d $\chi_{\text {avg }}^{2}=0.434$ ). Modeling mixtures of $0.05 \mathrm{M}$ methylglyoxal and amino acids (leucine, glycine and serine) in $\left(\mathrm{NH}_{4}\right)_{2} \mathrm{SO}_{4}$ also represent the experimental data (Figs. $4, \mathrm{~S} 8$, and $\mathrm{S} 9, \chi^{2} \geq 1.950$ ) poorly. Both semi-empirical models overestimate the surface tension depression using salt fit parameters, and underestimate with water fit parameters; however, the Henning model using salt fit parameters describes the experimental data best.

\subsection{Methylglyoxal/formaldehyde/acetaldehyde}

The experimental results of these mixtures have been previously published (Li et al., 2011). $0.05 \mathrm{M}$ total organic binary mixtures of acetaldehyde-methylglyoxal clearly show that the Schwier2010 semi-empirical model and the Henning semi-empirical model describe the experimental data well (Fig. 5a, c), and that the experimental data trend is clearly modeled using the salt fit parameters $\left(\chi_{\text {avg }}^{2}=0.337\right)$ instead of the water fit parameters $\left(\chi_{\mathrm{avg}}^{2}=6.027\right)$ for both models. Similar results are visible for $0.5 \mathrm{M}$ total organic concentrations of acetaldehyde-methylglyoxal and $0.5 \mathrm{M}$ total organic binary mixtures of formaldehyde-methylglyoxal (Figs. S10 and S11), although the Henning semi-empirical model performed better. Ternary mixtures of all three organics similarly show that both semi-empirical models using the salt parameter fits represent the experimental data well (Figs. 6 and S12).

\subsection{Complex organic mixtures}

Figure 7 shows a complex mixture of acetaldehyde, formaldehyde, glyoxal, methylglyoxal, oxalic acid, and succinic acid in $3.1 \mathrm{M}\left(\mathrm{NH}_{4}\right)_{2} \mathrm{SO}_{4}$ (total organic concentration ranged from 0 to $1 \mathrm{M}$ ). The Henning semi-empirical model, $\mathrm{S}$, describes the data best (Fig. $7 \mathrm{a}, \chi^{2}=0.820$ ); using the 


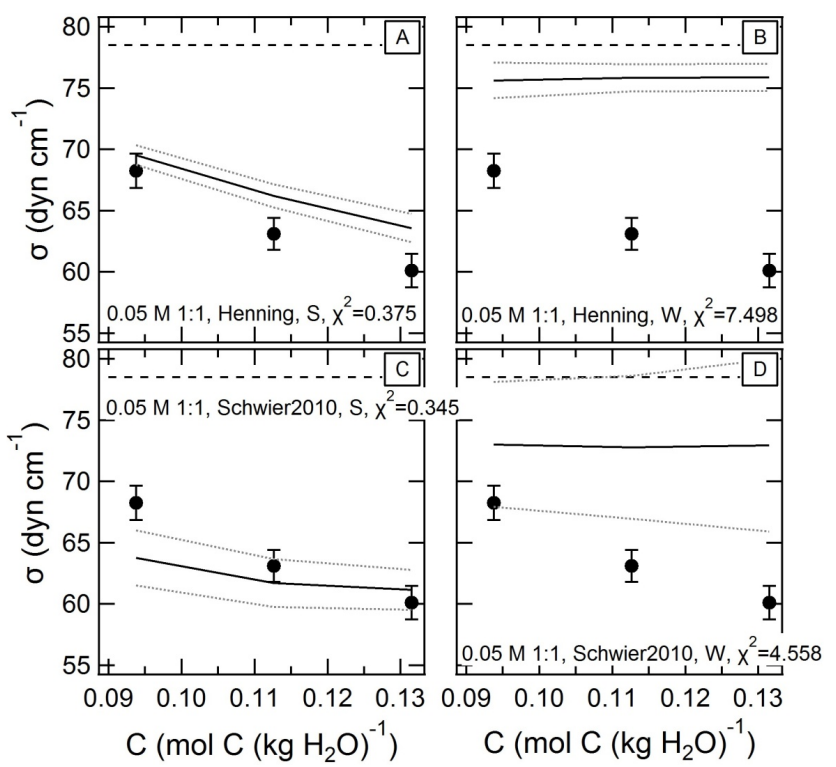

Fig. 6. $0.05 \mathrm{M}$ total organic with varying amounts of acetaldehyde: formaldehyde $(1: 1)$ and methylglyoxal in $3.1 \mathrm{M}$ $\left(\mathrm{NH}_{4}\right)_{2} \mathrm{SO}_{4}$. (A) and $(\mathbf{C})$ are the Henning semi-empirical model and Schwier2010 semi-empirical model with $\left(\mathrm{NH}_{4}\right)_{2} \mathrm{SO}_{4}$ fit parameters (S), respectively; (B) and (D) are the same with water fit parameters (W), respectively.

water fit parameters tends to underestimate the surface tension depression of the organics. The Schwier 2010 semiempirical model, S, clearly overestimates the surface tension depression of the experimental mixtures (Fig. 7c). This could be explained by the idea that most of the organic species present in this mixture are surface active and all are competing over a finite number of surface sites to form an organic monolayer coating. The Schwier2010 model does not take into account surface competition and assumes that each organic depresses the surface tension to its maximum capability, while in actuality the surface composition will be a mixture of the different organics with the excess organic in the bulk phase. Each organic has a different surface activity, so the actual surface tension of the mixture is higher than the idealized Schwier2010 semi-empirical model. However, at lower total organic concentrations, this issue should not be important.

\subsection{Explicit incorporation of salt-organic interactions}

While we have demonstrated the use of the salt fit parameters to incorporate salt effects directly into the S-L equation, we also tested the Tuckermann and modified Tuckermann equations (Eqs. 5, 6) to investigate the different methods of incorporating salt into the semi-empirical models. In control studies, we used Eq. (5) to determine $k$ values for all the isolated organics in $3.1 \mathrm{M}\left(\mathrm{NH}_{4}\right)_{2} \mathrm{SO}_{4}$ (Table S2), using $\sigma_{\mathrm{o}}=72.5 \mathrm{dyn} \mathrm{cm}^{-1}, \quad \mathrm{c}_{\text {salt }}=3.1 \mathrm{M}, \frac{\Delta \sigma}{\Delta c_{\text {salt }}}=2.1701 \mathrm{dyn} \mathrm{cm}^{-1}$

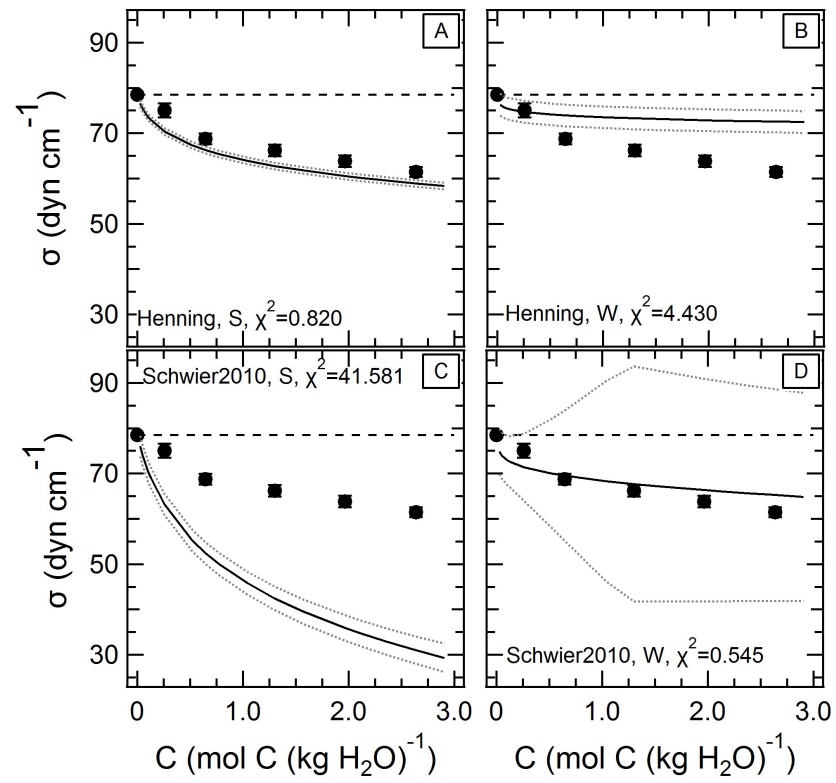

Fig. 7. Complex organic mixture (acetaldehyde, formaldehyde, glyoxal, methylglyoxal, oxalic acid, succinic acid) in $3.1 \mathrm{M}$ $\left(\mathrm{NH}_{4}\right)_{2} \mathrm{SO}_{4}$. (A) and (C) are the Henning semi-empirical model and Schwier2010 semi-empirical model with $\left(\mathrm{NH}_{4}\right)_{2} \mathrm{SO}_{4}$ fit parameters (S), respectively; (B) and (D) are the same with water fit parameters $(\mathrm{W})$, respectively.

$\mathrm{M}^{-1}$ (determined from the International Critical Tables, p.464 (Washburn, 2003)), and $T=298$ K. Using Eq. (6), we used the same parameters to determine $k$ values for our complex mixtures, shown in Table 1. These values were both positive and negative, and the sign of $k$ appears to be dependent on the dominant organic species present (i.e., most mixtures with acetaldehyde and methylglyoxal have a negative $k$ value, while those with glyoxal typically have a positive $k$ value). Table 3 shows a comparison of the goodness of fit $\left(\chi^{2}\right)$ of the different methods of salt incorporation: (1) using the modified Tuckermann equation (Eq. 6) or (2) using either the Henning model (Eq. 3) or Schwier2010 semiempirical model (Eq. 4) with salt fit parameters. Overall, the Tuckermann semi-empirical model describes the experimental data better for binary systems of different classes of organics (amino acid + carbonyl), but does not accurately describe binary and tertiary carbonyl reactive systems.

Additionally, Setschenow constants, $K_{s}$, have been used to describe the salting-out potential of organic compounds in high ionic strength solutions (Setschenow, 1889). However, most atmospherically relevant organics do not have known $K_{s}$ terms in $\left(\mathrm{NH}_{4}\right)_{2} \mathrm{SO}_{4}$ and these cannot be easily calculated. We have not incorporated the use of Setschenow constants in this work, although they do provide an additional modeling method for incorporating salt effects. 
Table 3. Experimental mixtures comparing the goodness of fit $\left(\chi^{2}\right)$ from the Henning and Schwier2010 semi-empirical models (Eqs. 3 and 4 , respectively), both using salt fit parameters, as well as from the modified Tuckermann equation (Eq. 6).

\begin{tabular}{llll}
\hline Mixture & \multicolumn{2}{c}{ Goodness of fit $\left(\chi^{2}\right)$ using salt fit parameters } & $\begin{array}{l}\text { Goodness of fit }\left(\chi^{2}\right) \text { using ex- } \\
\text { plicit salt-organic term }\end{array}$ \\
\hline & Henning model (Eq. 3$)$ & Schwier2010 model (Eq. 4) & Tuckermann model (Eq. 6) \\
\hline$\# 1$ & 0.06 & 0.07 & 0.05 \\
$\# 2$ & - & - & - \\
$\# 3$ & 0.34 & 0.41 & 0.13 \\
$\# 4$ & - & - & - \\
$\# 5$ & 0.23 & 0.76 & 0.08 \\
$\# 6$ & - & - & - \\
$\# 7$ & 2.13 & 7.55 & 0.22 \\
$\# 8$ & - & - & - \\
$\# 9$ & 0.03 & 0.03 & 0.21 \\
$\# 10$ & 1.95 & 3.35 & 0.46 \\
$\# 11$ & 3.88 & 17.05 & 0.76 \\
$\# 12$ & 0.26 & 0.58 & 0.21 \\
$\# 13$ & 2.63 & 7.88 & 1.41 \\
$\# 14$ & $0.59(0.05 \mathrm{M})$ & $0.08(0.05 \mathrm{M})$ & $2.54(0.05 \mathrm{M})$ \\
& $0.59(0.5 \mathrm{M})$ & $6.76(0.5 \mathrm{M})$ & $2.64(0.5 \mathrm{M})$ \\
$\# 15$ & 0.65 & 3.38 & 2.48 \\
$\# 16$ & $0.38(1: 1)$ & $0.35(1: 1)$ & $3.15(1: 1)$ \\
& $0.63(1: 3)$ & $0.23(1: 3)$ & $4.81(1: 3)$ \\
$\# 17$ & 0.82 & 41.58 & 0.63 \\
\hline
\end{tabular}

\section{Discussion and conclusions}

From all the experimental data and modeling framework presented, the Henning semi-empirical model (Eq. 3) and the Schwier2010 semi-empirical model (Eq. 4) perform similarly in reproducing experimental surface tension data of complex organic mixtures in $\mathrm{H}_{2} \mathrm{O}$ and $\left(\mathrm{NH}_{4}\right)_{2} \mathrm{SO}_{4}$, though the Henning semi-empirical model typically provides better $\chi^{2}$ values. The Henning model accounts for surface competition through the weighting term, $\psi_{i}$. This makes physical sense and also mathematically results in a reduced standard deviation for each semi-empirical model result. Unsurprisingly, applying salt S-L fit parameters (determined individually for each organic species in $\left.\left(\mathrm{NH}_{4}\right)_{2} \mathrm{SO}_{4}\right)$ where appropriate within the Henning model represents the experimental data more accurately than using water fit parameters in carbonyl reactive organic systems (methylglyoxal, formaldehyde, acetaldehyde). The standard deviation in some figures is very large; in these cases, the S-L equation does not adequately describe the surface tension depression data for the isolated organic species, leading to wider-range confidence intervals than for other isolated species.

Model performance is generally better for reactive systems consisting of structurally similar organic molecules with moderate surface tension depression. For carbonylcontaining species, cross-reaction products appear to have similar average surface-activity behavior to the reactants (possibly due to similar hydrophobic surface areas of the re- actants and products), which leads to systems that can be well described by the S-L equation and parameters solely based on the reactants (Schwier et al., 2010). However, if crossreaction products have very different properties from the reactants, additional terms may be needed to describe surface tension depression in the reactive mixture. Neither the semiempirical Henning model nor the Schwier2010 model characterizes the mixtures of methylglyoxal with amino acids well. This may be because the Mannich reaction products may have significantly different surface-bulk partitioning and surface-activity behavior than the reactants due to a large change in hydrophobic surface area, or because intermolecular reactions between the carbonyls and amino acids are not well represented within the semi-empirical models based on the S-L equation.

The compositions of the experimental systems described within this work mimic aerosol conditions near $100 \% \mathrm{RH}$ (near-saturation salt concentrations). For aerosol systems at higher relative humidity (> $100 \%$ RH), i.e., those at the condition of particle activation, the use of salt parameters may be inappropriate due to the higher water content at this point. Based on our results for organics in aqueous systems (Figs. 1, S1-3), to describe particle activation, if the dilute salt concentration is known, the Tuckermann approach (Eqs. 5 or 6) is preferred; if the ionic concentration is unknown, we recommend the use of the Henning semi-empirical model with water fit parameters. 
For aerosol conditions (up to $100 \% \mathrm{RH}$ ), we recommend the use of salt fit parameters in the Henning semi-empirical model (Eq. 3) over the Tuckermann approach, which uses water fit parameters (known more readily than salt fit parameters) but also requires an additional empirically determined parameter, $k$. The Henning (with salt parameters) and Tuckermann semi-empirical models provide similar modeling results and goodness-of-fit $\left(\chi^{2}\right)$ values, yet the Henning model is overall a simpler and more physical approach, requiring less empirically determined parameters. We recommend that the Henning model, with experimentally determined salt parameters, be used to incorporate implicit salt effects on complex mixtures in future aerosol surface tension studies and predictions of surfactant film formation in aerosols.

\section{Supplementary material related to this article is available online at http://www.atmos-chem-phys.net/13/ 10721/2013/acp-13-10721-2013-supplement.pdf.}

Acknowledgements. This work was funded by the NASA Tropospheric Chemistry program (grant NNX09AF26G). We thank Joseph Barakat, Nicole Lugo, Mark DeLuna, Christina Huang and Christian Tyroller for performing much of the preliminary and experimental data in this work. Special thanks to the Koberstein group at Columbia University for use of the pendant drop tensiometer. The authors gratefully acknowledge the editor for his useful comments and Carlos Argüello, Arseniy Kukanov, and Venkat Venkatasubramanian for their assistance on advanced statistical analysis.

Edited by: M. Gysel

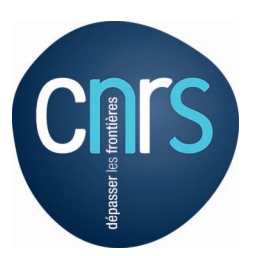

The publication of this article is financed by CNRS-INSU.

\section{References}

Adamson, A. W. and Gast, A. P., Physical chemistry of surfaces, Wiley, New York, 1997.

Anastasiadis, S. H., Chen, J. K., Koberstein, J. T., Siegel, A. F., Sohn, J. E., and Emerson, J. A.: The Determination of InterfacialTension by Video Image-Processing of Pendant Fluid Drops, J. Coll. Interf. Sci., 119, 55-66, doi:10.1016/0021-9797(87)90244X, 1987.

Asa-Awuku, A., Sullivan, A. P., Hennigan, C. J., Weber, R. J., and Nenes, A.: Investigation of molar volume and surfactant characteristics of water-soluble organic compounds in biomass burning aerosol, Atmos. Chem. Phys., 8, 799-812, doi:10.5194/acp8-799-2008, 2008.

Aumann, E. and Tabazadeh, A.: Rate of organic film formation and oxidation on aqueous drops, J. Geophys. Res., 113, D23205, doi:10.1029/2007JD009738, 2008.
Aumann, E., Hildemann, L. M., and Tabazadeh, A.: Measuring and modeling the composition and temperature-dependence of surface tension for organic solutions, Atmos. Environ., 44, 329-337, doi:10.1016/j.atmosenv.2009.10.033, 2010.

Blau, G., Lasinski, M., Orcun, S., Hsu, S.-H., Caruthers, J., Delgass, N., and Venkatasubramanian, V.: High fidelity mathematical model building with experimental data: A Bayesian approach, Comp. Chem. Eng., 32, 971-989, doi:10.1016/j.compchemeng.2007.04.008, 2008.

Booth, A. M., Topping, D. O., McFiggans, G., and Percival, C. J.: Surface tension of mixed inorganic and dicarboxylic acid aqueous solutions at $298.15 \mathrm{~K}$ and their importance for cloud activation predictions, Phys. Chem. Chem. Phys., 11, 8021-8028, doi:10.1039/B906849J, 2009.

Canny, J.: A Computational Approach to Edge Detection, IEEE Trans. Patt. Anal. Mach. Int., 8, 679-714, doi:10.1109/TPAMI.1986.4767851, 1986.

Cosman, L. M. and Bertram, A. K.: Reactive Uptake of $\mathrm{N}_{2} \mathrm{O}_{5}$ on Aqueous $\mathrm{H}_{2} \mathrm{SO}_{4}$ Solutions Coated with 1-Component and 2-Component Monolayers, J. Phys. Chem. A, 112, 4625-4635, doi:10.1021/jp8005469, 2008.

Cosman, L. M., Knopf, D. A., and Bertram, A. K.: $\mathrm{N}_{2} \mathrm{O}_{5}$ reactive uptake on aqueous sulfuric acid solutions coated with branched and straight-chain insoluble organic surfactants, J. Phys. Chem. A, 112, 2386-2396, doi:10.1021/jp710685r, 2008.

Dash, U. N. and Mohanty, B. K.: Thermodynamic functions of solutions of homologous dicarboxylic acids in water + acetone mixtures from surface tension measurements, Fluid Phase Equilibria, 134, 267-276, doi:10.1016/S0378-3812(97)00046-0, 1997.

De Haan, D. O., Corrigan, A. L., Smith, K. W., Stroik, D. R., Turley, J. J., Lee, F. E., Tolbert, M. A., Jimenez, J. L., Cordova, K. E., and Ferrell, G. R.: Secondary Organic Aerosol-Forming Reactions of Glyoxal with Amino Acids, Environ. Sci. Technol., 43, 28182824, doi:10.1021/es803534f, 2009a.

De Haan, D. O., Hawkins, L. N., Kononenko, J. A., Turley, J. J., Corrigan, A. L., Tolbert, M. A., and Jimenez, J. L.: Formation of Nitrogen-Containing Oligomers by Methylglyoxal and Amines in Simulated Evaporating Cloud Droplets, Environ. Sci. Technol., 45, 984-991, doi:10.1021/es102933x, 2010.

De Haan, D. O., Tolbert, M. A., and Jimenez, J. L.: Atmospheric condensed-phase reactions of glyoxal with methylamine, Geophys Res. Lett., 36, L11819, doi:10.1029/2009GL037441, 2009b.

Ekström, S., Nozière, B., and Hansson, H.-C.: The Cloud Condensation Nuclei (CCN) properties of 2-methyltetrols and C3C6 polyols from osmolality and surface tension measurements, Atmos. Chem. Phys., 9, 973-980, doi:10.5194/acp-9-973-2009, 2009.

Ervens, B. and Volkamer, R.: Glyoxal processing by aerosol multiphase chemistry: Towards a kinetic modeling framework of secondary organic aerosol formation in aqueous particles, Atmos. Chem. Phys., 10, 8219-8244, doi:10.5194/acp-10-82192010, 2010.

Facchini, M. C., Mircea, M., Fuzzi, S., and Charlson, R. J.: Cloud albedo enhancement by surface-active organic solutes in growing droplets, Nature, 401, 257-259, doi:10.1038/45758, 1999.

Facchini, M. C., Decesari, S., Mircea, M., Fuzzi, S., and Loglio, G.: Surface tension of atmospheric wet aerosol and cloud/fog droplets in relation to their organic carbon content 
and chemical composition, Atmos. Environ., 34, 4853-4857, doi:10.1016/S1352-2310(00)00237-5, 2000.

Fainerman, V. B. and Miller, R.: Simple Method to Estimate Surface Tension of Mixed Surfactant Solutions, The J. Phys. Chem. B, 105, 11432-11438, doi:10.1021/jp004179b, 2001.

Fainerman, V. B., Miller, R., and Aksenenko, E. V.: Simple model for prediction of surface tension of mixed surfactant solutions, Adv. Coll. Interf. Sci., 96, 339-359, doi:10.1016/S00018686(01)00088-4, 2002.

Gaman, A.: Binary homogeneous nucleation in water-succinic acid and water-glutaric acid systems, J. Chem. Phys., 120, 282, doi:10.1063/1.1630564, 2004.

Grosjean, D.: Formaldehyde and other carbonyls in Los Angeles ambient air, Environ. Sci. Technol., 16, 254-262, doi:10.1021/es00099a005, 1982.

Henning, S., Rosenørn, T., D’ Anna, B., Gola, A. A., Svenningsson, B., and Bilde, M.: Cloud droplet activation and surface tension of mixtures of slightly soluble organics and inorganic salt, Atmos. Chem. Phys., 5, 575-582, doi:10.5194/acp-5-575-2005, 2005.

Hitzenberger, R., Berner, A., Kasper-Giebl, A., Löflund, M., and Puxbaum, H.: Surface tension of Rax cloud water and its relation to the concentration of organic material, J. Geophys. Res., 107, 4752, doi:10.1029/2002JD002506, 2002.

$\mathrm{Hu}$, Y. F. and Lee, H.: Prediction of the surface tension of mixed electrolyte solutions based on the equation of Patwardhan and Kumar and the fundamental Butler equations, J. Coll. Interf. Sci., 269, 442-448, doi:10.1016/S0021-9797(03)00703-3, 2004.

Hyvärinen, A. R., Lihavainen, H., Gaman, A., Vairila, L., Ojala, H., Kulmala, M., and Viisanen, Y.: Surface tensions and densities of oxalic, malonic, succinic, maleic, malic, and cis-pinonic acids, J. Chem. Eng. Data, 51, 255-260, doi:10.1021/je050366x, 2006.

Juza, J.: The pendant drop method of surface tension measurement: Equation interpolating the shape factor tables for several selected planes, Czechoslovak J. Phys., 47, 351-357, doi:10.1023/A:1022808017830, 1997.

Kawamura, K. and Yasui, O.: Diurnal changes in the distribution of dicarboxylic acids, ketocarboxylic acids and dicarbonyls in the urban Tokyo atmosphere, Atmos. Environ., 39, 1945-1960, doi:10.1016/j.atmosenv.2004.12.014, 2005.

Keene, W. C., Pszenny, A. A. P., Maben, J. R., Stevenson, E., and Wall, A.: Closure evaluation of size-resolved aerosol $\mathrm{pH}$ in the New England coastal atmosphere during summer, J. Geophys. Res.-Atmos., 109 (D23), D23202, doi:10.1029/2004JD004801, 2004.

Kiss, G., Tombacz, E., and Hansson, H. C.: Surface tension effects of humic-like substances in the aqueous extract of tropospheric fine aerosol, J. Atmos. Chem., 50, 279-294, doi:10.1007/s10874005-5079-5, 2005.

Knopf, D. A. and Forrester, S. M.: Freezing of Water and Aqueous $\mathrm{NaCl}$ Droplets Coated by Organic Monolayers as a Function of Surfactant Properties and Water Activity, The J. Phys. Chem. A, 115, 5579-5591, doi:10.1021/jp2014644, 2011.

Langmuir, I.: The constitution and fundamental properties of solids and liquids. II. Liquids, J. Am. Chem. Soc., 39, 1848-1906, doi:10.1021/ja02254a006, 1917.

Li, Z. and Lu, B. C. Y.: Surface tension of aqueous electrolyte solutions at high concentrations - representation and prediction, Chemical Engineering Science, 56, 2879-2888, doi:10.1016/S0009-2509(00)00525-X, 2001.
Li, Z., Schwier, A. N., Sareen, N., and McNeill, V. F.: Reactive processing of formaldehyde and acetaldehyde in aqueous aerosol mimics: Surface tension depression and secondary organic products, Atmos. Chem. Phys., 11, 19477-19506, doi:10.5194/acpd11-19477-2011, 2011.

Li, Z. B., Li, Y. G., and Lu, J. F.: Surface Tension Model for Concentrated Electrolyte Aqueous Solutions by the Pitzer Equation, Ind. Eng. Chem. Res., 38, 1133-1139, doi:10.1021/ie980465m, 1999.

Li, Z. D., Williams, A. L., and Rood, M. J.: Influence of soluble surfactant properties on the activation of aerosol particles containing inorganic solute, J. Atmos. Sci., 55, 1859-1866, doi:10.1175/1520-0469(1998)055<1859:IOSSPO>2.0.CO;2, 1998.

Matijevic, E. and Pethica, B. A.: The properties of ionized monolayers, Part 1. Sodium dodecyl sulfate at the air/water interface, Trans. Faraday Soc., 54, 1383-1389, doi:10.1039/TF9585401382, 1958.

McNeill, V. F., Sareen, N., and Schwier, A. N.: SurfaceActive Organics in Atmospheric Aerosols, Topics Curr. Chem., doi:10.1007/128_2012_404, 2013.

Nopmongcol, U., Khamwichit, W., Fraser, M. P., and Allen, D. T.: Estimates of heterogeneous formation of secondary organic aerosol during a wood smoke episode in Houston, Texas, Atmos. Environ., 41, 3057-3070, doi:10.1016/j.atmosenv.2006.11.050, 2007.

Novakov, T. and Penner, J. E.: Large contribution of organic aerosols to cloud-condensation-nuclei concentrations, Nature, 365, 823-826, doi:10.1038/365823a0, 1993.

Nozière, B. and Córdova, A.: A Kinetic and Mechanistic Study of the Amino Acid Catalyzed Aldol Condensation of Acetaldehyde in Aqueous and Salt Solutions, J. Phys. Chem. A, 112, 28272837, doi:10.1021/jp7096845, 2008.

Nozière, B., Dziedzic, P., and Córdova, A.: Products and Kinetics of the Liquid-Phase Reaction of Glyoxal Catalyzed by Ammonium Ions $\left(\mathrm{NH}_{4}^{+}\right)$, J. Phys. Chem. A, 113, 231-237, doi:10.1021/jp8078293, 2009.

Nozière, B., Ekström, S., Alsberg, T., and Holmström, S.: Radical-initiated formation of organosulfates and surfactants in atmospheric aerosols, Geophys. Res. Lett., 37, L05806, doi:10.1029/2009GL041683, 2010.

Reid, J. P., Dennis-Smither, B. J., Kwamena, N. O., Miles, R. E. H., Hanford, K. L., and Homer, C. J.: The morphology of aerosol particles consisting of hydrophobic and hydrophilic phases: hydrocarbons, alcohols and fatty acids as the hydrophobic component, Phys. Chem. Chem. Phys., 13, 15559-15572, doi:10.1039/c1cp21510h, 2011.

Riipinen, I., Koponen, I. K., Frank, G. P., Hyvärinen, A. P., Vanhanen, J., Lihavainen, H., Lehtinen, K. E. J., Bilde, M., and Kulmala, M.: Adipic and Malonic Acid Aqueous Solutions: Surface Tensions and Saturation Vapor Pressures, The J. Phys. Chem. A, 111, 12995-13002, doi:10.1021/jp073731v, 2007.

Salma, I., Ocskay, R., Varga, I., and Maenhaut, W.: Surface tension of atmospheric humic-like substances in connection with relaxation, dilution, and solution pH, J. Geophys. Res.-Atmos., 111, D23205, doi:10.1029/2005JD007015, 2006.

Sareen, N., Schwier, A. N., Shapiro, E. L., Mitroo, D., and McNeill, V. F.: Secondary organic material formed by methylglyoxal 
in aqueous aerosol mimics, Atmos. Chem. Phys., 10, 997-1016, doi:10.5194/acp-10-997-2010, 2010.

Schwier, A. N., Sareen, N., Mitroo, D., Shapiro, E. L., and McNeill, V. F.: Glyoxal-methylglyoxal cross-reactions in secondary organic aerosol (SOA) formation, Environ. Sci. Technol., 44 (16), 6174-6182, doi:10.1021/es101225q, 2010.

Schwier, A. N., Mitroo, D., and McNeill, V. F.: Surface tension depression by low-solubility organic material in aqueous aerosol mimics, Atmos. Environ., 54, 490-495, doi:10.1016/j.atmosenv.2012.02.032, 2012.

Setschenow, J. Z.: Über die Constitution der Salzlösungen auf Grund ihres Verhaltens zu Kohlensäure, Z. Phys. Chem., 4, 117$125,1889$.

Shapiro, E. L., Szprengiel, J., Sareen, N., Jen, C. N., Giordano, M. R., and McNeill, V. F.: Light-absorbing secondary organic material formed by glyoxal in aqueous aerosol mimics, Atmos. Chem. Phys., 9, 2289-2300, doi:10.5194/acp-9-2289-2009, 2009.

Shulman, M. L., Jacobson, M. C., Carlson, R. J., Synovec, R. E., and Young, T. E.: Dissolution behavior and surface tension effects of organic compounds in nucleating cloud droplets, Geophys Res. Lett., 23, 277-280, doi:10.1029/95GL03810, 1996.

Suarez, J. T., Torres-Marchal, C., and Rasmussen, P.: Prediction of surface tensions of nonelectrolyte solutions, Chem. Eng. Sci., 44, 782-785, doi:10.1016/0009-2509(89)85055-9, 1989.

Svenningsson, B., Rissler, J., Swietlicki, E., Mircea, M., Bilde, M., Facchini, M. C., Decesari, S., Fuzzi, S., Zhou, J., Mønster, J., and Rosenørn, T.: Hygroscopic growth and critical supersaturations for mixed aerosol particles of inorganic and organic compounds of atmospheric relevance, Atmos. Chem. Phys., 6, 1937-1952, doi:10.5194/acp-6-1937-2006, 2006.

Szyrmer, W. and Zawadzki, I.: Biogenic and Anthropogenic Sources of Ice-Forming Nuclei: A Review, Bulletin of the American Meteorological Society, 78, 209-228, doi:10.1175/15200477(1997)078<0209:BAASOI>2.0.CO;2, 1997.

Tamura, M., Kurata, M., and Odani, H.: Practical Method for Estimating Surface Tensions of Solutions, Bull. Chem. Soc. Jpn., 28, 83-88, doi:10.1246/bcsj.28.83, 1955.

Tan, Y., Carlton, A. G., Seitzinger, S. P., and Turpin, B. J.: SOA from methylglyoxal in clouds and wet aerosols: Measurement and prediction of key products, Atmos. Environ., 44, 5218-5226, doi:10.1016/j.atmosenv.2010.08.045, 2010.
Tang, I. N. and Munkelwitz, H. R.: Water Activities, Densities, and Refractive-Indexes of Aqueous Sulfates and Sodium-Nitrate Droplets of Atmospheric Importance, J. Geophys. Res.-Atmos., 99, 18801-18808, doi:10.1029/94JD01345, 1994.

Tang, I. N., Tridico, A. C., and Fung, K. H.: Thermodynamic and optical properties of sea salt aerosols, J. Geophys. Res.-Atmos., 102, 23269-23275, doi:10.1029/97JD01806, 1997.

Topping, D. O., McFiggans, G. B., Kiss, G., Varga, Z., Facchini, M. C., Decesari, S., and Mircea, M.: Surface tensions of multicomponent mixed inorganic/organic aqueous systems of atmospheric significance: measurements, model predictions and importance for cloud activation predictions, Atmos. Chem. Phys., 7, 2371-2398, doi:10.5194/acp-7-2371-2007, 2007.

Tuckermann, R.: Surface tension of aqueous solutions of watersoluble organic and inorganic compounds, Atmos. Environ., 41, 6265-6275, doi:10.1016/j.atmosenv.2007.03.051, 2007.

Tuckermann, R. and Cammenga, H. K.: The surface tension of aqueous solutions of some atmospheric watersoluble organic compounds, Atmos. Environ., 38, 6135-6138, doi:10.1016/j.atmosenv.2004.08.005, 2004.

Varga, Z., Kiss, G., and Hansson, H. C.: Modelling the cloud condensation nucleus activity of organic acids on the basis of surface tension and osmolality measurements, Atmos. Chem. Phys., 7, 4601-4611, doi:10.5194/acp-7-4601-2007, 2007.

Wang, X., Gao, S., Yang, X., Chen, H., Chen, J., Zhuang, G., Surratt, J. D., Chan, M. N., and Seinfeld, J. H.: Evidence for High Molecular Weight Nitrogen-Containing Organic Salts in Urban Aerosols, Environ. Sci. Technol., 44, 4441-4446, doi:10.1021/es1001117, 2010.

Washburn, E. W., International Critical Tables Of Numerical Data, Physics, Chemistry and Technology ( $1^{\text {st }}$ Electronic Edition), 1926-1930, 2003.

Zhang, Q. and Anastasio, C.: Free and combined amino compounds in atmospheric fine particles $\left(\mathrm{PM}_{2.5}\right)$ and fog waters from Northern California, Atmos. Environ., 37, 2247-2258, doi:10.1016/S1352-2310(03)00127-4, 2003.

Zhang, Q., Jimenez, J. L., Worsnop, D. R., and Canagaratna, M.: A case study of urban particle acidity and its influence on secondary organic aerosol, Environ. Sci. Technol., 41, 3213-3219, doi:10.1021/es061812j, 2007. 